\title{
RESEARCH ARTICLE Geochemical Characteristics and Prospecting Prediction of Sediment in Songwang Area, Bobai County, Guangxi
}

\author{
Wai Yi \\ Guangxi Third Geological Team, Guangdong, Guangxi, 535000, China
}

Abstract: The characteristics of strata, structures, magmatic rocks, lithology and mineralization in Dongtao mining area (Songwang area) of Bobai County, Guangxi were summarized. According to the geochemical anomalies of sediment in water system, and the main anomalies are explained and evaluated, combined with the geological characteristics of Dongtao and other mining areas, the prospecting prediction of favorable areas is carried out, and it is considered that there is a good prospect of prospecting.

Keywords: Songwang area; Geochemical characteristics; Prospecting prediction

Citation: Wai Yi, 2019. Geochemical Characteristics and Prospecting Prediction of Sediment in Songwang Area, Bobai County, Guangxi. International Journal of Geology, 4(1): 1-3. http://doi.org/10.26789/IJG.2019.01.001

Copyright: Geochemical Characteristics and Prospecting Prediction of Sediment in Songwang Area, Bobai County, Guangxi. (C) 2019 Wai Yi. This is an Open Access article published by Urban Development Scientific Publishing Company. It is distributed under the terms of the Creative Commons Attribution-Noncommercial 4.0 International License, permitting all non-commercial use, distribution, and reproduction in any medium, provided the original work is properly cited and acknowledged.

\section{Introduction}

The survey area is located around Dongping Town, Songwang Town, Shuangwang Town, longtan town Town, Nabu Town, Shapo Town and Daba Town, which are about $40 \mathrm{~km} \sim 80 \mathrm{~km}$ south-west of Bobai County, Guangxi, with an area of about $400 \mathrm{~km}^{2}$. In recent years, the geological characteristics of this area have been roughly identified through the survey of stream sediments, soil profile and geological survey, and the relationship between strata, structures, magmatic activities and mineralization in this area has been analyzed, and the favorable areas for mineralization in this area have been predicted, which provides technical guidance and scientific basis for further geological work.

\section{Geological Survey}

The exposed strata in the investigated area include Lankeng Formation (Pt2-3lk) and Sheguang Formation (Pt2-3sg) of Yunkai Group in Middle and Upper Proterozoic, Liantan Formation of Lower Silurian (S11), Devonian (D), Xidong Formation of Cretaceous K2x and Quaternary (Q), among which Liantan Formation of Lower Silurian is the most exposed. All strata in the survey area have undergone deformation and metamorphism in different degrees. Especially in Yunkai Group and Silurian strata, Yunkai Group strata have undergone intense struc- tural deformation and metamorphism, resulting in new structural bedding, replacing the original bedding, causing the original sedimentary overlapping relationship to be destroyed or even disappeared, and the contact relationship between strata is mostly structural interface contact rather than normal sedimentary contact. Formed a mixed and disorderly tectonic stratigraphic sequence.

Magmatic rocks are well developed in the survey area, which are mainly acidic-moderately acidic intrusive rocks.

\section{Geochemical Anomaly Characteristics}

\subsection{Discrete Characteristics of Elements}

The variation coefficient of each geochemical sub-region (stratum) is counted. According to the statistical results, in the whole region, the element whose coefficient of change is greater than 3 is $\mathrm{Au}$; The elements greater than 1 are $\mathrm{Sn}, \mathrm{As}, \mathrm{Sb}, \mathrm{Cr}, \mathrm{Mn}, \mathrm{Co}, \mathrm{Ni}, \mathrm{Cu}, \mathrm{Zn}, \mathrm{Mo}, \mathrm{Cd}, \mathrm{w}, \mathrm{Pb}$ and bi; Elements less than 1 are Ag, p, Ti, La and v. The variation coefficient greater than 3 indicates that the distribution of $\mathrm{Au}$ elements in the region is uneven, and the possibility of local enrichment and mineralization is high, which is the main metallogenic and halo-forming element in the region. According to the statistical results of each sub-region, the variation coefficient of Au element combination in Devonian Lianhuashan Formation, Silurian 
Liantan Formation and Middle-Upper Proterozoic Yunkai Group is greater than 3, and the variation coefficient of $\mathrm{Au}$ element in Devonian Lianhuashan Formation is 8; In Liantan Formation of Silurian, the variation coefficient of Au element is 3.82. In Yunkai Group of Middle-Upper Proterozoic, the variation coefficient of Au element is 9. It shows that $\mathrm{Au}$ ore-forming elements are obviously enriched in the strata of Yunkai Group of Upper Proterozoic, Liantan Formation of Silurian and Lianhuashan Formation of Devonian. Moreover, at present, there have been gold deposits and folk gold mining and panning, so the gold prospecting work deserves attention.

\subsection{Characteristics of Geochemical Anomalies}

Element anomalies in the area have the following characteristics:

(1) The abnormal development of elements in the region is good. the elements with outer, middle and inner bands are $\mathrm{Au}, \mathrm{Ag}, \mathrm{As}, \mathrm{Sb}, \mathrm{w}, \mathrm{Pb}, \mathrm{Zn}, \mathrm{Cd}, \mathrm{Mo}, \mathrm{Cu}, \mathrm{Mn}, \mathrm{Sn}$, $\mathrm{Zn}, \mathrm{Ni}, \mathrm{Ti}, \mathrm{v}, \mathrm{Bi}, \mathrm{Co}$, etc. the elements with outer and middle bands are $\mathrm{La}$ and $\mathrm{p}$, among which the abnormal scale is larger. (2) There are $\mathrm{Zn}-\mathrm{Pb}-\mathrm{Ag}-\mathrm{Cu}-\mathrm{As}-\mathrm{Au}-\mathrm{Mo}-\mathrm{Sb}$ anomaly belt (HS-11) and $\mathrm{Pb}-\mathrm{Zn}-\mathrm{Ag}-\mathrm{Cu}-\mathrm{Mo}$ anomaly belt (HS-14) in the investigation area. These two anomalies are distributed in the northern part of the survey area. The former is located in Mazizi area on the west side of Dongtao $\mathrm{Pb}-\mathrm{Zn}$ Mine, while the latter is Dongtao $\mathrm{Pb}-\mathrm{Zn}$ Mine. The former is in the form of irregular strip string, while the latter is rectangular. (3) In the midwest of the survey area, along the contact zone between Liantan Formation of Silurian and Luchuan Rock Mass and Ningtan Rock Mass, an anomaly zone (HS-18) of $\mathrm{Sn}-\mathrm{Sn}-\mathrm{Pb}-$ $\mathrm{Mo}-\mathrm{Zn}-\mathrm{W} \mathrm{Cu}-\mathrm{As}-\mathrm{Ag}-\mathrm{Au}-\mathrm{Sb} \mathrm{Au}-\mathrm{Sb}$ was formed. The anomalies of Sn, Mo and other elements distributed along the Luchuan Rock Mass in the north-south direction in a long strip shape, and the anomaly concentration center mainly developed near Huangniye Village in the Luchuan Rock Mass. (4) In the Sheguang Formation of Yunkai Group of Middle-Upper Proterozoic in the middle-eastern part of the survey area, the AS-As - $\mathrm{Cu}-\mathrm{Zn}-\mathrm{Pb}-\mathrm{Ag}$ $\mathrm{Sb}$ anomaly belt (HS-24) was formed, and the anomalies were distributed in irregular strips and distributed in the north-south direction. (5) The Liude $\mathrm{Au}$-Sb - $\mathrm{As}$-Mo - Zn anomaly belt (HS-44) and Baishizhang Au -Sb- As -Mo -W anomaly belt (HS-46) were formed along the Liantan Formation of Silurian in the south and west of the survey area. The abnormal shape of this kind of anomaly is mainly irregular strip or beaded, and the distribution direction of the anomaly belt is roughly NE, which is consistent with the main faults in the survey area.

The similarity coefficient of elements not only reflects the degree of closeness between them, but also reflects some characteristics of geological processes from another aspect, implying genetic information. It is found that the elements in the survey area are mainly divided into five combinations from top to bottom: ( $\mathrm{Sn}, \mathrm{W}, \mathrm{Pb}, \mathrm{Bi}),(\mathrm{Cu}$, $\mathrm{Zn}, \mathrm{Mn}, \mathrm{Ti}, \mathrm{Cr}, \mathrm{Co}, \mathrm{Ni}, \mathrm{V}, \mathrm{P}),(\mathrm{Ag}, \mathrm{Cd}, \mathrm{Mo})$, (La), (Au, Sb, As), which respectively represent high temperature hydrothermal fluids related to acid magmatism.

(1) Comprehensive anomaly of sn, $\mathrm{w}, \mathrm{Pb}$ and $\mathrm{Bi}$ : this is a group of high-temperature hydrothermal element combinations closely related to acid magmatism. Compared with other horizons, the background value of Luchuan pluton in the west of the survey area is obviously higher. Therefore, in this survey area, the abnormal distribution of this group of elements can well indicate the hidden rock mass in the survey area.

(2) Comprehensive anomalies of $\mathrm{Cu}, \mathrm{Zn}, \mathrm{Mn}, \mathrm{Ti}, \mathrm{Cr}$, $\mathrm{Co}, \mathrm{Ni}, \mathrm{V}$ and $\mathrm{P}$ : This is a group of high-temperature hydrothermal element combinations closely related to basic-ultrabasic magmatic activities, and their high background and anomalies are mainly distributed in the intrusion area of basic-ultrabasic magmatic rocks, and no outcrops of basic-ultrabasic magmatic rocks are found in the investigation area, all according to the high background of this group of elements.

(3) Comprehensive anomaly of $\mathrm{Ag}, \mathrm{Cd}$ and $\mathrm{Mo}$, and comprehensive anomaly of $\mathrm{Au}, \mathrm{As}$ and $\mathrm{Sb}$ respectively represent the combination of silver and molybdenum mineralization elements of medium-low temperature hydrothermal type and gold mineralization elements of medium-low temperature hydrothermal type. The abnormal distribution of elements in this group is extremely uneven in the survey area, especially in Devonian, Silurian and Yunkai Group strata, and the variation coefficients of element combinations are all greater than 1.5 , especially the variation coefficients of $\mathrm{Au}$ and $\mathrm{Sb}$ in Devonian are all greater than 3 , indicating that local mineralization may be larger in this group of strata.

(4) La anomaly: it is a rare earth element in the region. The statistical results of element background distribution characteristics and variation coefficient show that the variation coefficient is small, and the fluctuation of background value between strata is not large, showing relatively independent distribution characteristics.

\subsection{Geochemical Anomaly Characteristics of Typical Deposits in the Survey Area}

\subsubsection{Geochemical Characteristics of Dongtao Lead-Zinc Mine Area}

The mining area is located $5 \mathrm{Km}$ away from the north- 
east of Songwang Town, Bobai County. The exposed area of Lankeng Formation of Yunkai Group in Upper Proterozoic is $4.0 \mathrm{Km}^{2}$, which is the ore-bearing strata in the mining area. At present, seven layers of lead-zinc mineralization have been discovered, and the mining area is still in the mining state.

There are good geochemical anomalies of $\mathrm{Pb}$ and $\mathrm{Ag}$ in the mining area, among which 14 are $\mathrm{Pb}$ anomalies, and the anomaly centers are relatively concentrated, with abundant values ranging from 100 to $900 \times 10^{-6}$. There are 5 anomalies of $\mathrm{Ag}$, the range of which basically overlaps with $\mathrm{Pb}$ anomaly, the anomaly center is relatively concentrated, and the abundance value is $2 \times 10^{-6} . \mathrm{Pb}$ and $\mathrm{Ag}$ anomalies are basically consistent with the outcrop distribution of ore bodies, especially $\mathrm{Pb}$ anomalies, which can be used as direct or indirect basis for prospecting.

\subsubsection{Geochemical Characteristics of Songwang W-Sn-Mo Deposit}

The mining area is located $2 \mathrm{Km}$ away from the west of Songwang Town, Bobai County. At present, $20 \mathrm{~W}-\mathrm{Sn}-\mathrm{Mo}$ ore bodies have been delineated in the mining area. Some ore bodies are distributed in the inner and outer contact zone of the Huaguoling granite porphyry plant, controlled by the NNE fissure, some ore bodies occur in the nearly NNE altered crushed rock zone, and a few ore bodies occur in the reticulated Shi Ying veinlets of migmatite. The average grade of main ore bodies is $0.15 \sim 0.286 \%$, and the associated Mo is $0.001 \sim 0.13 \%$. There are chloritization, calcite and silicification alteration.

According to the survey of $1 / 50,000$ stream sediments carried out in this area in the past, comprehensive anomalies have been circled in the mining area, and the abnormal elements include W, Sn and Mo. Concentration centers are mainly distributed in the mining area. The maximum values of abnormal elements are w: $360 \times 10^{-6}$, sn: $400 \times 10^{-6}$, mo: $20 \times 10^{-6}$. According to the discovery of the surface trench, the abnormal concentration in the central part, and through drilling, many tungsten and tin ore bodies have been found, among which the No.3 ore body has a large scale. It is proved that the anomaly is caused by tungsten-tin ore body, and the geochemical anomaly is used to find ore in this area, and the effect is remarkable.

\section{Prospecting Prediction}

The NE-trending fault in the mining area is the main structure in this area, and its main lithology is crushed altered breccia and Shi Ying vein. In the south and west of the survey area, there are also obvious gold anomalies, which are mainly irregular strips or beads. It was revealed and verified by trenching engineering that gold mineralized bodies existed, and it was also proved that the gold anomaly in this area was ore-induced anomaly.

Through relevant geological work, highly weathered lead-zinc mineralized bodies were also found on the surface. By collecting the data of boreholes and tunnels in Dongtao $\mathrm{Pb}-\mathrm{Zn}$ mine area, it is also found that there are $\mathrm{Pb}-\mathrm{Zn}$ ore bodies extending towards the periphery along the strike, which is in good agreement with the $\mathrm{Pb}-\mathrm{Zn}$ anomaly delineated by geochemical exploration institute.

The rhyolite porphyry, quartz porphyry and migmatite are revealed from different parts of some boreholes constructed in Dongtao mining area. The discovery of copper mineralization in individual boreholes in the mining area and the discovery of copper ore bodies in the northeast side of the periphery of the mining area indicate the existence of copper ore bodies. Tungsten, tin, molybdenum and copper deposits have been found in the external contact zone of late Yanshanian granite in this area. According to the analysis of mineral metallogenic temperature zoning characteristics, the discovered $\mathrm{Ag}-\mathrm{Pb}-\mathrm{Zn}$ ore bodies are distributed in the middle and low temperature metallogenic zoning, and the underlying $\mathrm{Cu}-\mathrm{Pb}-\mathrm{Zn}$ metallogenic belt and W-Sn-Mo metallogenic belt may be formed, which has a great prospecting prospect in the mining area.

\section{References}

[1] Guangxi Bureau of Geology and Mineral Resources, The Annal of Regional geology of Guangxi Zhuang Autonomous Region [m]. Beijing Geological Publishing House, 1985.77-156.

[2] Liu Chongmin, Hu Shuqi and Ma Shengming. Geochemical Exploration of Hydrothermal Polymetallic Ore [M]. Beijing Geological Publishing House, 2014.14-57.

[3] Yao Fengliang, Sun Fengyue. A Course in Mineral Deposits [M]. Beijing Geological Publishing House, 2006. 